Published in final edited form as:

Curr Opin Nephrol Hypertens. 2010 March ; 19(2): 153-159. doi:10.1097/MNH.0b013e328335f939.

\title{
Health-related quality of life outcomes in Chronic kidney disease
}

\author{
Ritu K. Soni, MD ${ }^{1}$, Steven D. Weisbord, MD, MSc ${ }^{1,2,3}$, and Mark L. Unruh, MD, MSc ${ }^{4}$ \\ ${ }^{1}$ Department of Medicine, University of Pittsburgh Medical Center, Pittsburgh, PA \\ ${ }^{2}$ Center for Health Equity Research and Promotion, VA Pittsburgh Healthcare System, Pittsburgh, \\ PA \\ ${ }^{3}$ Renal Section, Medical Specialty Service Line, VA Pittsburgh Healthcare System, Pittsburgh, PA \\ ${ }^{4}$ Renal-Electrolyte Division, Department of Medicine, University of Pittsburgh Medical Center, \\ Pittsburgh, PA
}

\section{Abstract}

Purpose of Review-Patients with CKD endure compromised health-related quality of life (HRQOL). Although the link between HRQOL and increased mortality in ESRD patients is welldocumented, less is known about the relationship between CKD and HRQOL. This article reviews the recent evidence on HRQOL, its correlates and proposed intervention strategies to improve HRQOL in CKD.

Recent findings-A growing body of literature indicates that various co-morbid conditions related to CKD play a substantial role in the impaired HRQOL in CKD. Hypertension, both a cause and complication of CKD, negatively affects HRQOL due to associated co-morbidities, side effects from anti-hypertensive medications and awareness of the diagnosis. Anemia has been associated with HRQOL, but concerns about the safety of erythropoietin-stimulating agents (ESA) have led to more conservative anemia treatment. Frailty, symptom burden and depression are also major contributory factors to HRQOL in CKD.

Summary-Certain determinants of HRQOL in CKD, namely anemia and depression are treatable. Early identification and correction may improve overall well-being of patients. Clinical trials are required to demonstrate whether treatment interventions benefit HRQOL in this high-risk population. Furthermore, whether integration of HRQOL assessment into routine clinical practice will improve HRQOL outcomes remains to be determined.

\section{Keywords}

Chronic kidney disease; quality of life; hypertension; anemia; frailty; symptom burden

\section{Introduction}

In recent years, there has been a growing interest in understanding the health-related quality of life (HRQOL) of patients with chronic kidney disease. It is now widely accepted that

Direct correspondence and reprint requests to: Mark Unruh MD MS, Assistant Professor of Medicine, Renal-Electrolyte Division, University of Pittsburgh School of Medicine, 200 Lothrop Street, PUH C-1111, Pittsburgh, PA 15213, Phone (412) 647-2571, Fax (412) $647-4787$.

Support and Financial Disclosure Declaration

This work was supported by NIH DK66006 and DK77785 (Unruh). Dr. Unruh also receives grant support from the Paul Teschan Research Fund, Norman Coplon Research Award, and the Baxter Extramural Grant Program. Dr. Unruh serves on the Medical Advisory Board for Baxter Healthcare. Dr. Weisbord is supported by a VA Health Services Research and Development Career Development Transition Award (03-176) 
HRQOL is significantly compromised in patients with end-stage renal disease (ESRD) and HRQOL has been associated with increased mortality and morbidity [1**,2]. The importance of measuring HRQOL in ESRD patients is further highlighted by the adoption by the Center for Medicare Services of a mandatory requisite of routine measurement of HRQOL at all dialysis units [2,3]. While there is a growing understanding of HRQOL and its determinants in ESRD [4,5,6,7], little is known about the HRQOL in the CKD population.

HRQOL reflects the contribution of disease to the patients' sense of well-being and may serve as a valuable tool to assess the effectiveness of therapeutic interventions. In fact, the goals of treatment of CKD in developed nations have evolved over time from mere survival to achievement of a certain level of well-being [8]. Figure 1 demonstrates factors that have been described as contributors to HRQOL in CKD. There seems to be some inconsistency in what is considered a predictor or component of HRQOL. For instance, pain is measured as one of the aspects of HRQOL but is also associated with diminished HRQOL. The purpose of this article is to review the recent evidence on HRQOL and its correlates in various health states in pre-dialysis CKD patients and synthesize the related implications for optimizing care in this vulnerable population.

\section{Chronic Kidney Disease and HRQOL}

With only a handful of large-scale studies [1**], HRQOL in CKD patients not on renal replacement therapy remains relatively understudied. Mujais et al. [1**] observed that patients with CKD had significant impairment in HRQOL, with the most pronounced decrement being in physical function, as measured by the Kidney Disease Quality of Life (KDQOL) questionnaire. Women and older patients ( $>65 \mathrm{yr}$ ) had worse HRQOL scores, as did patients with diabetes, anemia and cardiovascular co-morbidities. Additionally, they noticed a progressive decline in HRQOL with worsening renal function (Figure 2). Furthermore, HRQOL was found to decline over time, with the main predictors of this decline being age, co-morbidities and changes in hemoglobin and albumin levels. Noteworthy is a study by Molsted et al. [9], the results of which were comparable to the study by Mujais and colleagues, except for a significant association between smoking and HRQOL reported in the former. The strength of these studies is that they used the KDQOL questionnaire, which assesses diseasespecific HRQOL. However, the study by Mujais et al. [1**]was limited by loss of patients to follow-up and the one by Molsted et al. [9] suffered from non-responder bias and a small study population of patients with $\mathrm{CKD}(\mathrm{n}=63)$.

There have been reviews of the evidence by Kutner citing favorable HRQOL outcomes with management of pre-ESRD care, anemia, sleep disorders, exercise programs and treatment of depression [10]. However, much of this evidence for exercise, sleep disorders and physical activity was synthesized from older adults in the general population or ESRD and whether these findings extrapolate to patients with CKD remains to be tested.

\section{Hypertension and HRQOL}

Hypertensive patients have been shown to experience a significant reduction in HRQOL compared to normotensive subjects $\left[11,12^{*}, 13^{*}, 14^{*}\right]$. Hypertension is both a cause and a complication of CKD, and is a well established risk factor for CKD progression [15].

Furthermore, CKD and hypertension are independent risk factors for cardiovascular disease $[15,16]$, the latter being recognized as a leading contributor to global burden of disease [17]. Li et al. [11] conducted a cross-sectional survey in the Chinese population and observed that awareness of the diagnosis and poorly controlled hypertension were associated with significantly impaired HRQOL. A more recent population-based study in China by Wang and colleagues [14*] reported marked deterioration of HRQOL in hypertensive individuals, while co-existing co-morbidities further worsened HRQOL scores. Two small clinic-based studies 
in Brazil $[12 *, 18]$ published results that were in accordance with the study by Wang and colleagues. In addition to the association between hypertension on decrements in HRQOL, a cross-sectional analysis of hypertensive Nigerian patients by Ogunlana et al. [19*] also identified symptom count and co-morbidity, particularly stroke and visual impairment, as major predictors of HRQOL. When assessing the impact of hypertension on HRQOL, the extent to which one should account for co-morbidity has been a challenge for investigators since one can reason that hypertension would alter HRQOL through end-organ damage such as stroke, cardiovascular disease, or CKD.

It is not surprising that these studies reported conflicting results in terms of impact of hypertension across the different aspects of HRQOL. For instance, most of the studies showed that hypertension negatively affected physical function $\left[11,12^{*}, 13^{*}, 14^{*}\right]$, Ogunlana and colleagues $\left[19^{*}\right]$ demonstrated a greater impact on the mental component score (MCS) and total quality of life score and Cavalcante et al. [18] reported differences in the emotional component and quality of sex life in a small, cross-sectional study. There are several possible reasons for the discrepant findings including differences in study populations, the use of varying HRQOL instruments, use of different anti-hypertensives with different side-effect profiles, disease severity and presence of co-morbidities. Since hypertension is a putatively asymptomatic condition, it has been presumed that the poor HRQOL among hypertensive individuals is attributable to complications or co-morbidities $\left[12^{*}, 14^{*}, 19^{*}\right]$, knowledge of the diagnosis or 'labeling' phenomenon $\left[11,12^{*}, 13^{*}, 18,19^{*}\right]$, and/or adverse effects from antihypertensive medications $\left[11,12^{*}, 13^{*}, 18\right]$.

While the correlation between hypertension and HRQOL has been studied in patients with ESRD, there is a considerable gap in our understanding of HRQOL in hypertensive CKD [20]. The African American Study of Kidney Disease and Hypertension (AASK) was a trial of HRQOL exclusively among African Americans with hypertension and CKD [21]. The results of the study were consistent with the results in other populations, with the conclusion that hypertension substantially affected the physical dimensions of HRQOL relative to mental dimensions. Additionally, several clinical and demographic factors (employment status, education level, household income, body mass index, co-morbidity, duration of hypertension and number of anti-hypertensives prescribed, exercise status and male sex) were found to be independent predictors of HRQOL. The AASK study further demonstrated that there were no differences in the HRQOL for different levels of blood pressure control [20]. The impact of blood pressure level on HRQOL was also examined in a sub-study of the Hypertension Optimal Treatment (HOT) Study [22,23], which reported that lower levels of diastolic blood pressure were linked to better HRQOL as assessed by the Psychological General Well-Being index. However, more intense anti-hypertensive therapy was associated with a slight increase in subjective symptoms [23]. The seeming inconsistency in HRQOL findings between the AASK and HOT studies could be explained by longer follow-up, sicker patients and different HRQOL instruments used by the AASK study.

Considering the dramatically increasing prevalence of CKD, the risk of progression of CKD with hypertension [15] and the significant impact of the disease on HRQOL, improving HRQOL is emerging as one of the therapeutic goals in hypertensive individuals. However, there is a need for more studies in the CKD population to better understand the associations described. Of note, the planned NHLBI-SPRINT study of intensive blood pressure lowering will include participants with CKD Stage 3 [24].

\section{Anemia and HRQOL}

Anemia is highly prevalent in patients with CKD and is associated with adverse clinical outcomes [25] and diminished HRQOL [26,27,28,29,30**,31]. An extensive body of research 
has established that treatment of anemia in CKD with erythropoietin-stimulating agents (ESAs) has a favorable impact on HRQOL [26,27,28,29,30**]. However, the large number of HRQOL assessment tools used, variability in data reporting and heterogeneity of patient populations in these studies make interpretation of the magnitude and nature of these improvements challenging. Studies using the Short Form 36 (SF-36) and Kidney Disease Questionnaire (KDQ) indices have shown greater impact on the physical domains, vitality, and performance $\left[28,30^{* *}, 32\right]$ whereas studies that employed the Sickness Impact Profile (SIP) scale revealed greater improvement in psychosocial dimensions of HRQOL [30**]. Additional domains not measured by commonly used instruments that have been shown to improve with ESAs include sleep $\left[29,30^{* *}\right]$, cognitive functioning and sexual functioning [30**,32].

The use of ESAs has become a routine practice in CKD patients in an effort to correct anemia and improve HRQOL. Nonetheless, two simultaneously published trials $\left[33^{*}, 34\right]$ raised concerns regarding the optimal hemoglobin target levels. Drueke et al. [33*], the CREATE investigators, reported significant increment in HRQOL with higher hemoglobin levels (Figure 3) whereas Singh et al. [34], the CHOIR investigators, reported no difference in the HRQOL between the low and high hemoglobin arms after EPO therapy. Additionally, normalization of hematocrit was shown to be associated with adverse cardiovascular outcomes in the CHOIR trial [34]. These trials were subject to extensive critique [35,36,37], which prompted a series of subsequent studies and systematic reviews that supported the ineffectiveness of normalization of hemoglobin, suggesting that maximal improvement in HRQOL occurred in the range of 10.0-12.0 g/dL, with blunting of the beneficial effects at higher levels [30**,38, $\left.39^{* *}\right]$.

In consideration of the conflicting results of these publications, the National Kidney Foundation Kidney Disease Outcomes Quality Initiative (NKF KDOQI) published revised guidelines for the management of anemia in CKD patients [40], which were further reviewed at the Kidney Disease: Improving Global Outcomes (KDIGO) international conference [41]. Members voiced a general consensus on maintaining target hemoglobin levels in the range of 11.0 to $12.0 \mathrm{~g} / \mathrm{dL}$ [40] and acknowledged the potential for harm associated with levels higher than $13.0 \mathrm{~g} / \mathrm{dL}[40,41]$.

Although the favorable effect of anemia correction on HRQOL is well recognized, the endeavor to identify optimal hemoglobin targets that limit the adverse outcomes in patients persists. Currently ongoing trials are expected to provide further clarification on this issue [40].

\section{Frailty and CKD}

There is a limited but growing literature examining the association between frailty and CKD. Frailty is an increasingly recognized biological syndrome that is related to, but distinct from aging, co-morbidity and disability [42]. It is characterized by diminished physiologic reserves, functional decline and increased vulnerability to acute stressors [43]. Fried et al. [44] proposed a well-validated screening tool, which defines frailty as the presence of $\geq 3$ criteria: slow gait, unintentional weight loss, low physical activity, exhaustion and/or poor grip strength. A crosssectional analysis by Shilpak et al. [45] found an independent association between CKD and frailty in community-dwelling elderly persons. Johansen et al.[46]reported a strong association between ESRD and frailty, even in younger age groups. Supporting evidence for these findings comes from a study by Wilhelm-Leen et al. [47**] which demonstrated that the prevalence of frailty was significantly higher in persons with CKD, and that this association was stronger in persons with more severe CKD. The biological mechanisms contributing to frailty in CKD are thought to involve a complex interplay of elevated inflammatory biomarkers, hormonal changes (declining levels of testosterone, vitamin $\mathrm{D}$, growth hormone and thyroid abnormalities), malnutrition, anemia, sarcopenia and depression [43,48]. It is also notable that 
studies investigating the impact of vitamin D replacement on HRQOL in vitamin D deficient CKD patients are currently ongoing [49]. However, the association between frailty and CKD in the study by Wilhelm-Leen and colleagues was present despite adjustment for these potential mediators $\left[47^{* *}\right]$.

Frailty is an independent predictor of adverse health outcomes, including hospitalization, disability and mortality [44]. A study by Kanauchi et al. [50] identified a significantly lower HRQOL among frail clinic patients with cardiometabolic risk factors, than their non-frail counterparts. Masel et al. [51] further confirmed the association between frailty and impaired HRQOL in older Mexican Americans. Combining these results with the data reporting an association between CKD and impaired HRQOL [1**,2,8], it appears that frail individuals with CKD are highly susceptible to adverse health outcomes and poor HRQOL. This is supported by studies that found an independent association of frailty with mortality in patients with CKD [47**] and ESRD [46]. Additional evidence comes from the study by Kanauchi and colleagues [50], that found that patients with lower creatinine clearance had significantly lower scores on the World Health Organization Quality of Life-26 questionnaire.

The increasing prevalence of CKD in the older population [52] and the poor prognosis and impaired HRQOL associated with frailty warrant early identification of high-risk patients. Suggested management strategies to prevent further deterioration include exercise training and correction of malnutrition, anemia, depression and hormonal imbalances [48]. Growth hormone supplementation in elderly dialysis patients has been shown to improve muscle performance [48] and HRQOL [53], but whether this approach would be helpful in patients with non-dialysis dependent CKD remains to be established.

\section{Symptom burden, Depression and HRQOL}

The expanding awareness about objective parameters and their impact on HRQOL is complemented by few studies on subjective symptoms and their influence on HRQOL in CKD $[10,54 * *, 55]$. The symptom burden that these patients struggle with include, fatigue $[2,10$, $54 * *]$, cognitive difficulties [2,54**], sleep disturbances [ $1 * *, 2,10,54 * *, 56]$, sexual dysfunction $[2,54 * *]$, pain $[2,10,54 * *, 56]$ and depression $[2,10,54 * *]$, most of which are interlinked $\left[1^{* *}, 10\right]$. While larger studies on pre-dialysis CKD patients are lacking, existing ones confirm the negative impact of these symptoms on HRQOL $[2,55,56]$.

Abdel-Kader et al. demonstrated through two cross-sectional studies [54**,57**], that patients with advanced CKD (Stages 4-5) and ESRD report a comparable compromise in HRQOL, which may help to guide patients and providers on expectations following dialysis initiation. Furthermore, the study that addressed the symptom burden [54**]documented that both of these patient populations are afflicted with a similar symptom burden and have a similar prevalence of depression, whereas the other [57**]addressed individual factors affecting HRQOL and concluded that family and health were the most prominent patient-identified dimensions influencing HRQOL.

Although the detrimental role of symptoms on HRQOL in CKD is now better recognized, they are often under-treated despite availability of effective therapies for most symptoms and depression [10,55]. Symptoms including pain, sexual dysfunction, and depression have been shown to be effectively treated in the ESRD population. Whether interventions aimed at alleviating such bothersome symptoms translate into improved HRQOL in the ESRD and CKD populations is a matter of ongoing investigation. 


\section{Conclusion}

CKD has a profound effect on HRQOL with the most prominent areas of difficulty being the physical domains. While the link between HRQOL and increased hospitalizations and mortality in ESRD is well characterized [1**], a parallel association in CKD patients remains unexplored. Further insights are needed into effective interventional strategies and their impact on HRQOL. Given the numerous factors contributing to HRQOL in CKD (Figure 1), whether intervention in a single aspect would translate into better HRQOL remains to be shown. With identification of CKD as a rising global health and economic burden[58], a better understanding of HRQOL issues would enable providers to deliver more patient-centered care and improve overall well-being of patients.

\section{References and recommended reading}

Papers of particular interest, published within the annual period of review, have been highlighted as:

* of special interest

** of outstanding interest

** 1. Mujais SK, Story K, Brouillette J, et al. Health-related quality of life in CKD Patients: correlates and evolution over time. Clin J Am Soc Nephrol 2009 Aug;4(8):1293-1301. This is one of the few large scale studies documenting the impaired HRQOL in CKD. Furthermore, HRQOL declined over time. Age, co-morbidities, hemoglobin and albumin level were the main predictors of HRQOL. [PubMed: 19643926]

2. Finkelstein FO, Wuerth D, Finkelstein SH. Health related quality of life and the CKD patient: challenges for the nephrology community. Kidney Int. 2009 Aug 12;

3. O'Shaughnessy DV, Elder GJ. Review article: Patient-level outcomes: the missing link. Nephrology (Carlton) 2009 Jun;14( 4):443-451. [PubMed: 19563387]

4. Liem YS, Bosch JL, Hunink MG. Preference-based quality of life of patients on renal replacement therapy: a systematic review and meta-analysis. Value Health 2008 Jul-Aug;11(4):733-741. [PubMed: 18194399]

5. Tamura MK. Incidence, management, and outcomes of end-stage renal disease in the elderly. Curr Opin Nephrol Hypertens 2009 May;18( 3):252-257. [PubMed: 19374012]

6. Kring DL, Crane PB. Factors affecting quality of life in persons on hemodialysis. Nephrol Nurs J 2009 Jan-Feb;36(1):15-24. 55. [PubMed: 19271620]

7. Chiu YW, Teitelbaum I, Misra M, et al. Pill burden, adherence, hyperphosphatemia, and quality of life in maintenance dialysis patients. Clin J Am Soc Nephrol 2009 Jun;4( 6):1089-1096. [PubMed: 19423571]

8. Unruh ML, Hess R. Assessment of health-related quality of life among patients with chronic kidney disease. Adv Chronic Kidney Dis 2007 Oct;14( 4):345-352. [PubMed: 17904501]

9. Molsted S, Prescott L, Heaf J, et al. Assessment and clinical aspects of health-related quality of life in dialysis patients and patients with chronic kidney disease. Nephron Clin Pract 2007;106( 1):c24-33. [PubMed: 17409766]

10. Kutner NG. Promoting functioning and well-being in older CKD patients: review of recent evidence. Int Urol Nephrol 2008;40( 4):1151-1158. [PubMed: 18787971]

11. Li W, Liu L, Puente JG, et al. Hypertension and health-related quality of life: an epidemiological study in patients attending hospital clinics in China. J Hypertens 2005 Sep;23( 9):1667-1676. [PubMed: 16093911]

* 12. de Gusmao JL, Mion D Jr, Pierin AM. Health-related quality of life and blood pressure control in hypertensive patients with and without complications. Clinics (Sao Paulo) 2009;64(7):619-628. This study showed that hypertension was associated with poor HRQOL. Hypertensive individuals with complications had worse HRQOL than those without complications. [PubMed: 19606236] 
* 13. Hayes DK, Denny CH, Keenan NL, et al. Health-related quality of life and hypertension status, awareness, treatment, and control: National Health and Nutrition Examination Survey, 2001--2004. J Hypertens 2008 Apr;26(4):641-647. This observational study of 8303 individuals showed that having hypertension, being aware of it and the use of anti-hypertensive medications was associated with lower HRQOL. Blood pressure control status did not impact HRQOL. [PubMed: 18327071]

* 14. Wang R, Zhao Y, He X, et al. Impact of hypertension on health-related quality of life in a populationbased study in Shanghai, China. Public Health 2009 Aug;123(8):534-539. This cross-sectionaly survey of 919 individuals showed that hypertension significantly impairs HRQOL. Co-existing comorbidities further worsened HRQOL in hypertensive subjects. [PubMed: 19665154]

15. K/DOQI clinical practice guidelines on hypertension and antihypertensive agents in chronic kidney disease. Am J Kidney Dis 2004 May;43( 5 Suppl 1):S1-290. [PubMed: 15114537]

16. Norris K, Bourgoigne J, Gassman J, et al. Cardiovascular outcomes in the African American Study of Kidney Disease and Hypertension (AASK) Trial. Am J Kidney Dis 2006 Nov;48( 5):739-751. [PubMed: 17059993]

17. Ikeda, N. Understanding the decline of mean systolic blood pressure in Japan: an analysis of pooled data from the National Nutrition Survey, 1986-2002. 2008. [cited 8 6]; 90 9-988]. Available from: http://www.who.int/bulletin/volumes/86/12/07-050195/en/

18. Cavalcante MA, Bombig MT, Luna Filho B, et al. Quality of life of hypertensive patients treated at an outpatient clinic. Arq Bras Cardiol 2007 Oct;89( 4):245-250. [PubMed: 17992381]

* 19. Ogunlana MO, Adedokun B, Dairo MD, et al. Profile and predictor of health-related quality of life among hypertensive patients in south-western Nigeria. BMC Cardiovasc Disord 2009;9:25. This cross-sectional study of 265 hypertensive African patients reported limitations in physical functions associated with hypertension. Increasing blood pressure, symptom count, presence of visual disturbances or stroke as complications were negative determinants of HRQOL. [PubMed: 19534800]

20. Lash JP, Wang X, Greene T, et al. Quality of life in the African American Study of Kidney Disease and Hypertension: effects of blood pressure management. Am J Kidney Dis 2006 Jun;47( 6):956964. [PubMed: 16731290]

21. Kusek JW, Greene P, Wang SR, et al. Cross-sectional study of health-related quality of life in African Americans with chronic renal insufficiency: the African American Study of Kidney Disease and Hypertension Trial. Am J Kidney Dis 2002 Mar;39( 3):513-524. [PubMed: 11877570]

22. Hansson L. The Hypertension Optimal Treatment study and the importance of lowering blood pressure. J Hypertens Suppl 1999 Feb;17( 1):S9-13. [PubMed: 10340838]

23. Wiklund I, Halling K, Ryden-Bergsten T, et al. Does lowering the blood pressure improve the mood? Quality-of-life results from the Hypertension Optimal Treatment (HOT) study. Blood Press 1997 Nov;6( 6):357-364. [PubMed: 9495661]

24. Systolic Blood Pressure Intervention Trial (SPRINT) Coordinating Center. 2008. Available from: https://www.fbo.gov/index? $\mathrm{s}=$ opportunity \&mode=form \&tab=core $\& \mathrm{id}=\mathrm{cd} 350 \mathrm{f} 54 \mathrm{~d} 6 \mathrm{e} 1 \mathrm{e} 6 \mathrm{bb} 59789 \mathrm{af638 \textrm {e }} 8 \mathrm{abdc} \&$ _cview=0

25. Dowling TC. Prevalence, etiology, and consequences of anemia and clinical and economic benefits of anemia correction in patients with chronic kidney disease: an overview. Am J Health Syst Pharm 2007 Jul 1;64(13 Suppl 8):S3-7. quiz S23-25. [PubMed: 17591994]

26. Kimel M, Leidy NK, Mannix S, et al. Does epoetin alfa improve health-related quality of life in chronically ill patients with anemia? Summary of trials of cancer, HIV/AIDS, and chronic kidney disease. Value Health 2008 Jan-Feb;11(1):57-75. [PubMed: 18237361]

27. Lefebvre P, Vekeman F, Sarokhan B, et al. Relationship between hemoglobin level and quality of life in anemic patients with chronic kidney disease receiving epoetin alfa. Curr Med Res Opin 2006 Oct;22( 10):1929-1937. [PubMed: 17022852]

28. Alexander M, Kewalramani R, Agodoa I, et al. Association of anemia correction with health related quality of life in patients not on dialysis. Curr Med Res Opin 2007 Dec;23( 12):2997-3008. [PubMed: 17958944]

29. Hansen RA, Chin H, Blalock S, et al. Predialysis chronic kidney disease: evaluation of quality of life in clinic patients receiving comprehensive anemia care. Res Social Adm Pharm 2009 Jun;5( 2):143153. [PubMed: 19524862] 
** 30. Leaf DE, Goldfarb DS. Interpretation and review of health-related quality of life data in CKD patients receiving treatment for anemia. Kidney Int 2009 Jan;75(1):15-24. This review summarises the literature on anemia treatment in CKD and its impact on HRQOL, concluding that the maximum improvement in HRQOL occurs with hemoglobin levels between 10-12 g/dL and higher leves are associated with adverse cardiovascular complications. [PubMed: 18813284]

31. Finkelstein FO, Story K, Firanek C, et al. Health-related quality of life and hemoglobin levels in chronic kidney disease patients. Clin J Am Soc Nephrol 2009 Jan;4( 1):33-38. [PubMed: 18987300]

32. Weisbord SD, Kimmel PL. Health-related quality of life in the era of erythropoietin. Hemodial Int 2008 Jan;12( 1):6-15. [PubMed: 18271834]

* 33. Drueke TB, Locatelli F, Clyne N, et al. Normalization of hemoglobin level in patients with chronic kidney disease and anemia. N Engl J Med 2006 Nov 16;355(20):2071-2084. This randomized trial of 603 CKD patients with anemia revealed significant improvement in HRQOL with higher hemoglobin levels with erythropoietin therapy. [PubMed: 17108342]

34. Singh AK, Szczech L, Tang KL, et al. Correction of anemia with epoetin alfa in chronic kidney disease. N Engl J Med 2006 Nov 16;355( 20):2085-2098. [PubMed: 17108343]

35. Singh AK, Szczech L, Tang KL, et al. Anaemia of CKD--the CHOIR study revisited. Nephrol Dial Transplant 2007 Jul;22( 7):1806-1810. [PubMed: 17420166]

36. Levin A. Understanding recent haemoglobin trials in CKD: methods and lesson learned from CREATE and CHOIR. Nephrol Dial Transplant 2007 Feb;22( 2):309-312. [PubMed: 17234670]

37. Kutner N. Quality of life assessment in a recent haemoglobin trial in CKD (CHOIR). Nephrol Dial Transplant 2007 Jul;22( 7):2099. [PubMed: 17395656]

38. Ritz E, Laville M, Bilous RW, et al. Target level for hemoglobin correction in patients with diabetes and CKD: primary results of the Anemia Correction in Diabetes (ACORD) Study. Am J Kidney Dis 2007 Feb;49( 2):194-207. [PubMed: 17261422]

** 39. Clement FM, Klarenbach S, Tonelli M, et al. The impact of selecting a high hemoglobin target level on health-related quality of life for patients with chronic kidney disease: a systematic review and meta-analysis. Arch Intern Med 2009 Jun 22;169(12):1104-1112. This systematic review and meta-analysis of 11 trials on anemic CKD patients suggested that anemia correction to hemoglobin range of $9-12 \mathrm{~g} / \mathrm{dL}$ has a favorable impact on HRQOL, with a blunting of improvement beyond 12 g/dL. [PubMed: 19546410]

40. KDOQI Clinical Practice Guideline and Clinical Practice Recommendations for anemia in chronic kidney disease: 2007 update of hemoglobin target. Am J Kidney Dis 2007 Sep;50( 3):471-530. [PubMed: 17720528]

41. Locatelli F, Nissenson AR, Barrett BJ, et al. Clinical practice guidelines for anemia in chronic kidney disease: problems and solutions. A position statement from Kidney Disease: Improving Global Outcomes (KDIGO). Kidney Int 2008 Nov;74( 10):1237-1240. [PubMed: 18596731]

42. Fried LP, Ferrucci L, Darer J, et al. Untangling the concepts of disability, frailty, and comorbidity: implications for improved targeting and care. J Gerontol A Biol Sci Med Sci 2004 Mar;59( 3):255263. [PubMed: 15031310]

43. Hamerman D. Toward an understanding of frailty. Ann Intern Med 1999 Jun 1;130( 11):945-950. [PubMed: 10375351]

44. Fried LP, Tangen CM, Walston J, et al. Frailty in older adults: evidence for a phenotype. J Gerontol A Biol Sci Med Sci 2001 Mar;56( 3):M146-156. [PubMed: 11253156]

45. Shlipak MG, Stehman-Breen C, Fried LF, et al. The presence of frailty in elderly persons with chronic renal insufficiency. Am J Kidney Dis 2004 May;43( 5):861-867. [PubMed: 15112177]

46. Johansen KL, Chertow GM, Jin C, et al. Significance of frailty among dialysis patients. J Am Soc Nephrol 2007 Nov;18( 11):2960-2967. [PubMed: 17942958]

** 47. Wilhelm-Leen ER, Hall YN, Tamura MK, et al. Frailty and chronic kidney disease: the Third National Health and Nutrition Evaluation Survey. Am J Med 2009 Jul;122(7):664-671. e662. This study demonstrated that the prevalence of frailty was significantly higher in patients with CKD, and that this association was stronger with more severe CKD. [PubMed: 19559169]

48. Abdel-Rahman, E. Association Between CKD and Frailty and Prevention of Functional Losses. Available from: http://www.asn-online.org/education_and_meetings/geriatrics/Chapter34.pdf 
49. Moe, S. Comparison of Cholecalciferol Versus Doxercalciferol in the Treatment of Secondary Hyperparathyroidism in Chronic Kidney Disease Stage Three and Four. 2007. Available from: http://clinicaltrials.gov/ct2/show/NCT00285467

50. Kanauchi M, Kubo A, Kanauchi K, et al. Frailty, health-related quality of life and mental well-being in older adults with cardiometabolic risk factors. Int J Clin Pract 2008 Sep;62( 9):1447-1451.

[PubMed: 18643932]

51. Masel MC, Graham JE, Reistetter TA, et al. Frailty and health related quality of life in older Mexican Americans. Health Qual Life Outcomes 2009;7:70. [PubMed: 19627598]

52. Coresh J, Selvin E, Stevens LA, et al. Prevalence of chronic kidney disease in the United States. JAMA 2007 Nov 7;298( 17):2038-2047. [PubMed: 17986697]

53. Feldt-Rasmussen B, Lange M, Sulowicz W, et al. Growth hormone treatment during hemodialysis in a randomized trial improves nutrition, quality of life, and cardiovascular risk. J Am Soc Nephrol 2007 Jul;18( 7):2161-2171. [PubMed: 17554147]

** 54. Abdel-Kader K, Unruh ML, Weisbord SD. Symptom burden, depression, and quality of life in chronic and end-stage kidney disease. Clin J Am Soc Nephrol 2009 Jun;4(6):1057-1064. This is study compared the symptom burden, prevalence of depression and HRQOL in CKD and ESRD patients, reporting no significant difference in both groups. These results may help guide patients and providers on expectations following dialysis initiation. [PubMed: 19423570]

55. Weisbord SD. Symptoms and their correlates in chronic kidney disease. Adv Chronic Kidney Dis 2007 Oct;14( 4):319-327. [PubMed: 17904498]

56. Cohen SD, Patel SS, Khetpal P, et al. Pain, sleep disturbance, and quality of life in patients with chronic kidney disease. Clin J Am Soc Nephrol 2007 Sep;2( 5):919-925. [PubMed: 17702733]

** 57. Abdel-Kader K, Myaskovsky L, Karpov I, et al. Individual quality of life in chronic kidney disease: influence of age and dialysis modality. Clin J Am Soc Nephrol 2009 Apr;4 (4):711-718. This report examined individual and psychosocial factors associated with HRQOL in patients with CKD. Family and health were the most prominent patient-reported dimensions influencing HRQOL. [PubMed: 19339411]

58. K/DOQI clinical practice guidelines for chronic kidney disease: evaluation, classification, and stratification. Am J Kidney Dis 2002 Feb;39( 2 Suppl 1):S1-266. [PubMed: 11904577] 


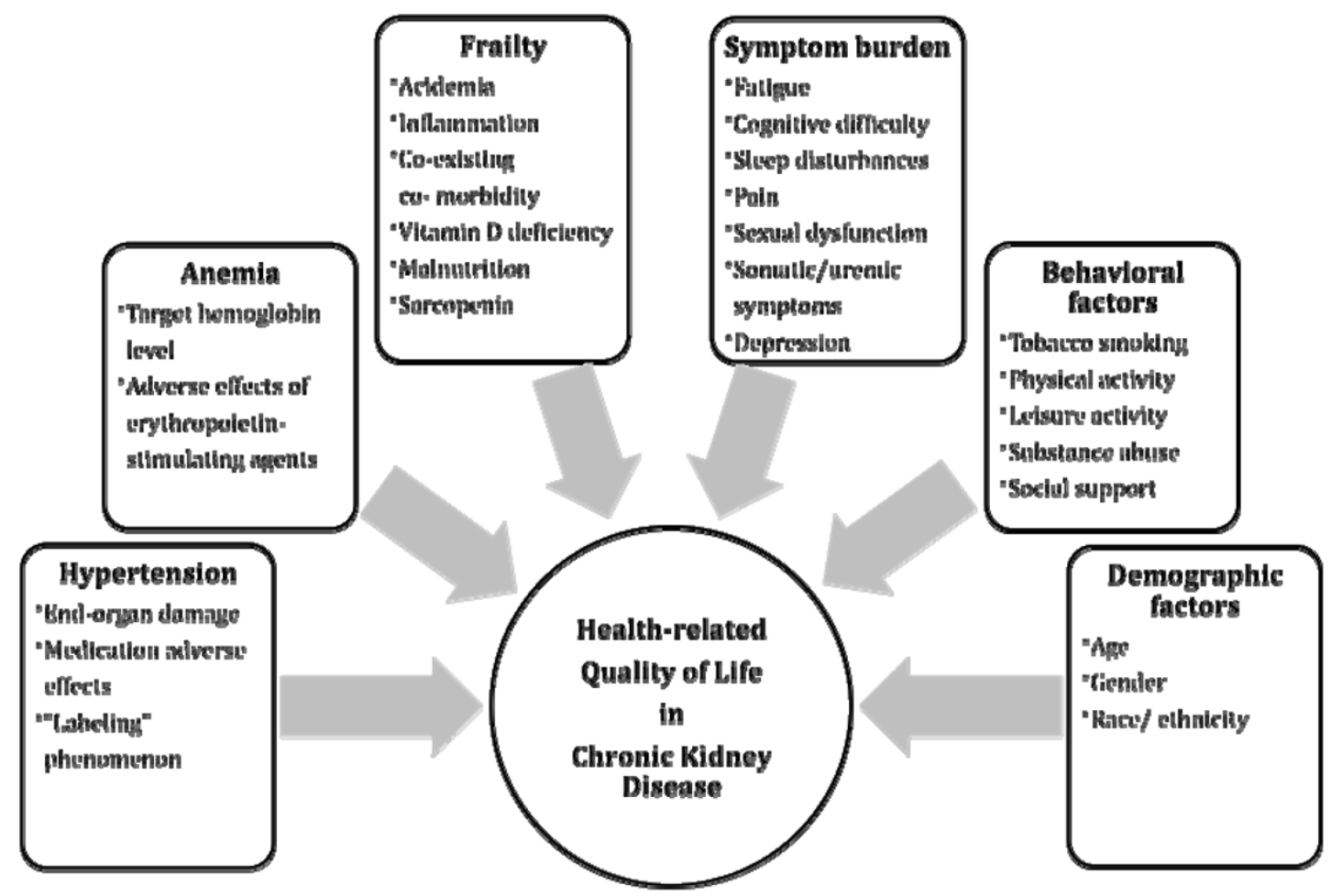

Figure 1.

Factors contributing to health-related quality of life in chronic kidney disease (ORIGINAL) 


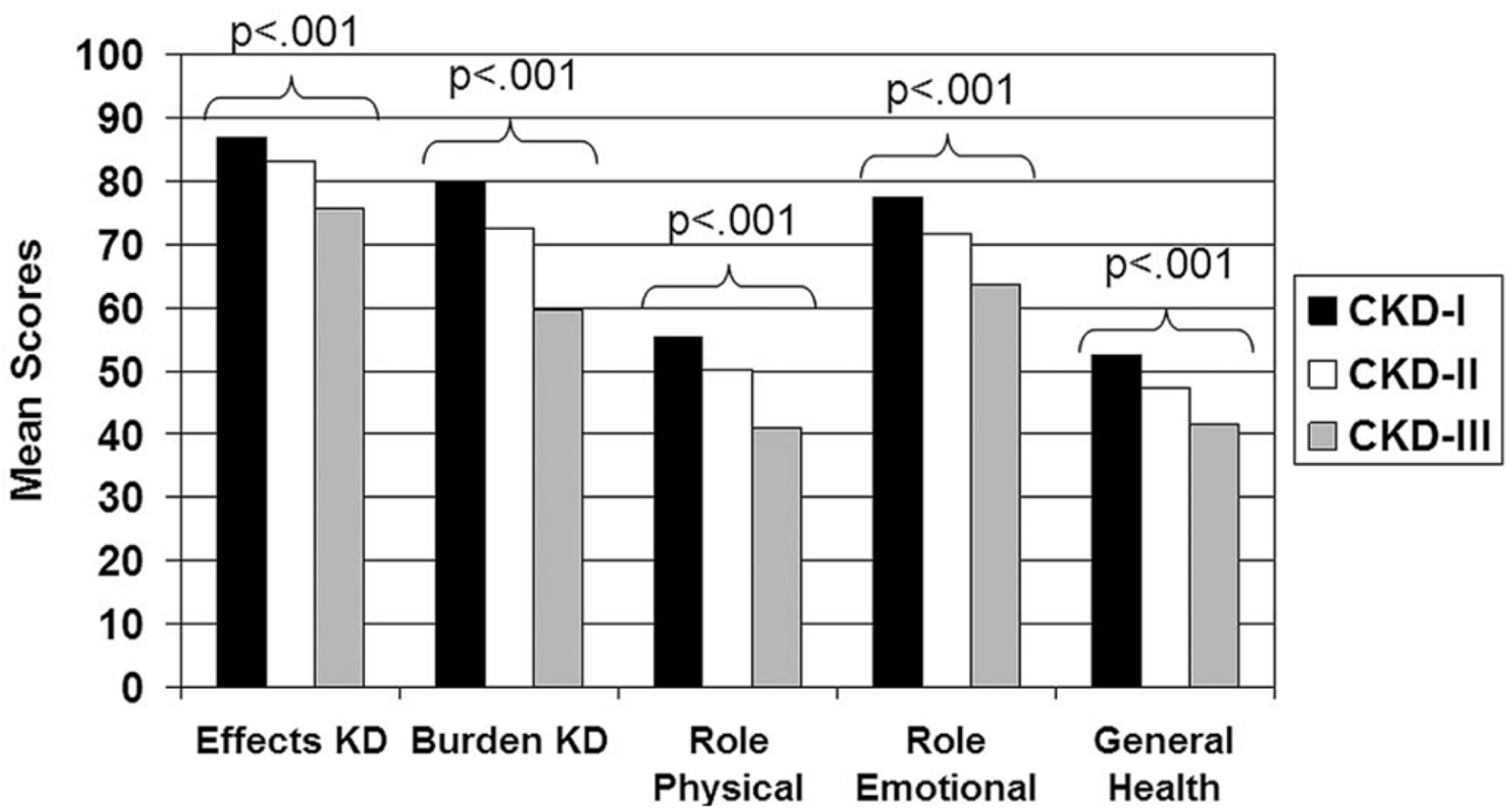

Figure 2.

Examples of several domains of the health-related quality of life (HRQOL) showing the progressive decline in scores with the more advanced stages of chronic kidney disease (CKD). Statistical significant values are for the trend across the three CKD stages. 


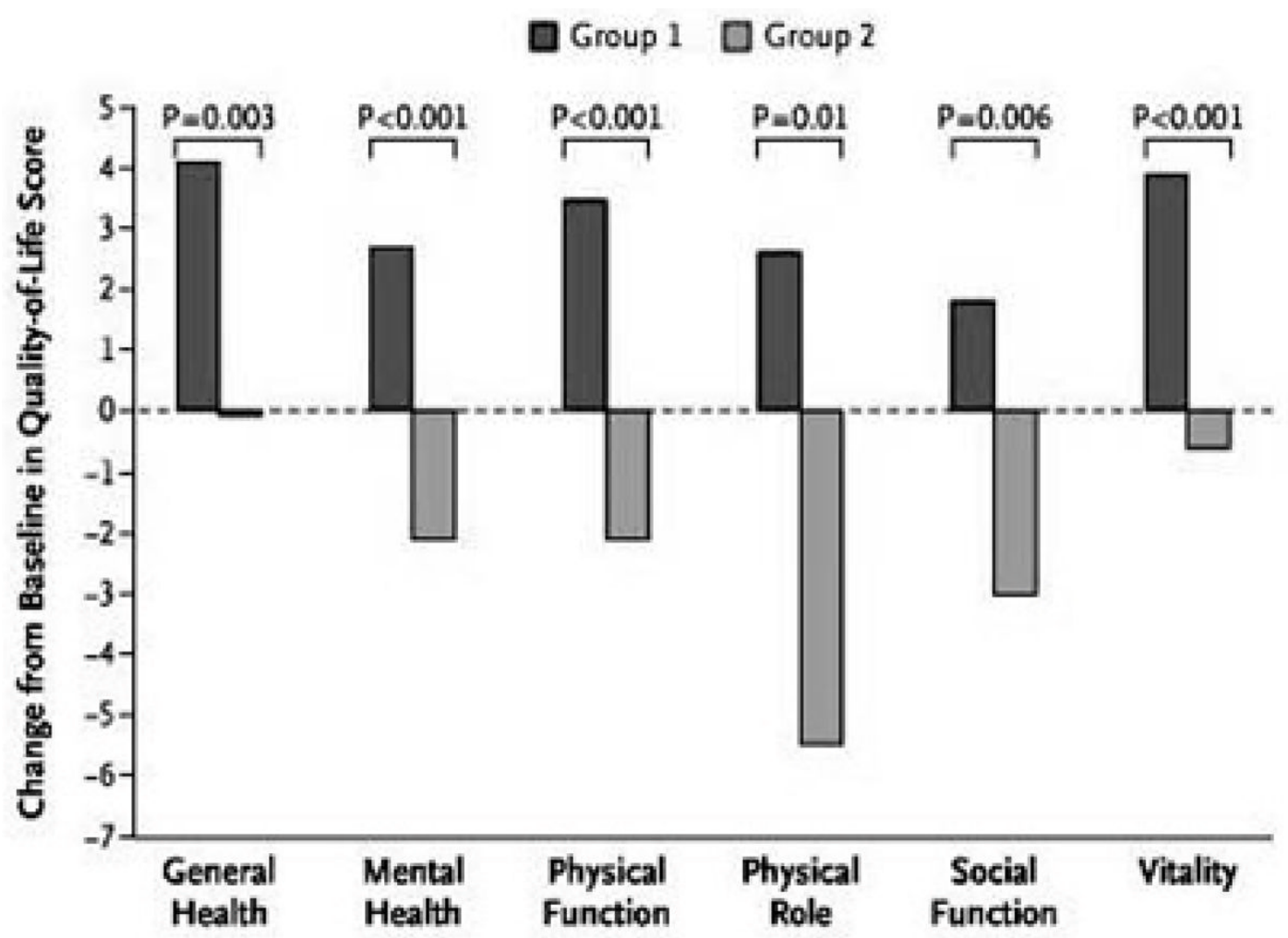

Figure 3.

Changes from baseline to Year 1 in Short Form Survey Instrument (SF-36) Health related Quality of Life Scores with erythropoietin treatment for anemic CKD patients in the CREATE Study [33*]. Group 1: Target hemoglobin range 13-15 g/dL. Group 2: Target hemoglobin range 10.5-11.5 g/dL. Positive changes indicate improvement in, and negative changes worsening of, the health related quality of life. 